\title{
MEASURING REGIONAL PROGRESS TOWARDS SDG 3 WITH GEOSPATIAL AND STATISTICAL INFORMATION - A CASE STUDY OF DEQING COUNTY
}

\author{
WANG Qianwen, FAN Deqin, QIU Yue, MIAO Yuanqing
}

College of Geoscience and Surveying Engineering, China University of Mining and Technology (Beijing), Beijing, China wqw_cumt@yeah.net, kinly129@163.com, qiuyue1993@hotmail.com, yuanqingmiao@yeah.net

\author{
Commission IV, ICWG IV/III, WG IV/4
}

KEY WORDS: SDG 3, Localization, Geospatial, Accessibility, Assessment

\begin{abstract}
:
The 17 Sustainable Development Goals (SDGs) were proposed in 2030 Agenda for Sustainable Development of the United Nations in 2015, in which SDG 3 is about ensuring healthy lives and promoting well-being for all ages. The assessment on SDG 3 helps to measure or monitor the level of sustainable and healthy development of nation or sub-nation regions. However, the SDG 3 is mainly aimed at the global or national levels, and lack of quantitative assessment and analysis. Therefore, this paper, taking Deqing County of Zhejiang Province in China as an example, presents a pilot study which measured county-level SDG 3 by using statistical information and geospatial information. There are three main steps: Firstly, a set of localized indicators for SDG 3 was built according to adaptability, scalability, and coverage, combined with the specific conditions of Deqing County. Secondly, the selected indicators were calculated by combining integration of statistical and geospatial information. Thirdly, an assessment based on dashboard was processed. The results showed that 12 of the 15 health-related indicators in Deqing County were evaluated as green, 1 was yellow, and 2 were gray. The morbidity rate and mortality rate of infectious diseases in $2010 \sim 2017$ are low and essential health-care services are equally covered in space. This study provides scientific basis for the management of healthy and sustainable development in Deqing County, and provides a reference example for monitoring and evaluation of SDG 3 in other regions.
\end{abstract}

\section{INTRODUCTION}

To boost the economic prosperity, social inclusion, and environmental protection in developed and developing countries, 2030 Agenda for Sustainable Development of the United Nations in September 2015 (United Nations, 2015), putting forward 17 Sustainable Development Goals (SDGs), 169 targets and 234 indicators, which is a major public policy guiding the development of the world in the next 15 years. Quantitative assessment and dynamic monitoring of SDGs are important measures in implementing the UN 2030 Agenda for Sustainable Development (Chen, 2018). SDG 3, aiming to "ensure healthy lives and promote well-being for all at all ages", is the guarantee to execute sustainable development strategies. Health is an inevitable requirement for people's all-round development and a basic condition for economic development. It can directly affect the sustainable development level of a region. Therefore, it is of great significance to study the practice of SDG 3 in a country or even a region.

At present, organizations in the world mainly conduct summary analysis and health evaluation of health indicators on a global or national scale. The World Health Organization's (2016) World Health Statistics 2016, as a special issue of SDG health monitoring, explored the content of SDG health-related indicators; Institute for Health Metrics and Evaluation (IHME) of the University of Washington conducted a baseline study of the 2015 health-related SDG goals worldwide, and conducted an overall evaluation of health goals with comprehensive indicators such as SDG index and Socio-demographic Index (GBD 2015 SDG Collaborators, 2016); Based on the IHME study, Yu analyzed the scores of health-related SDG indicators of 188 countries and regions in the world, and pointed out the baseline level of global and Chinese SDG in 2015 (Yu, 2017) ; On this basis, Yu further explored the implementation status of health-related SDG indicators in China in 2017, predicted the scores of health-related SDG indicators in 2030 and proposed policy recommendations for the realization of relevant SDGs (Yu, 2018);

There is a growing body of work examining the implementation of health and sustainable development in one aspect of health indicators in the country or region. Building upon the work of the Commission on Investing in Health and published estimates of feasible global mortality SDG 3 targets, Eduardo analysed Mexico's mortality to assess the feasibility of reducing premature (0-69 years) mortality and propose a path to meet SDG 3 (Eduardo, 2016); Kuuire proposed changes in the use of maternal health services in Nigeria and Malawi for several consecutive years, indicating that poverty, wealth and various environmental issues can promote and inhibit maternal health care services (Kuuire, 2017); Blackstone analyzed data from the 2013 Nigeria Demographic and Health Survey (NDHS) report to explore the relationship between structural and intermediary maternal characteristics and likelihood of childhood mortality (Blackstone, 2017); Rood presented an analytical framework to evaluate the use of TB case notification rates $(\mathrm{CNR})$ to monitor and to evaluate $\mathrm{TB}$ under-detection and under-diagnoses in Bangladesh (Rood, 2019).

In summary, the SDG 3 is mainly aimed at the global or national levels, and lack of quantitative assessment and analysis. How to measure the progress towards SDG 3 of a small region accurately need to be discussed. This paper, taking Deqing County as an example, presents a pilot study which measured county-level SDG 3 by using statistical information and geospatial information.

\section{MATERIALS}

\subsection{Study Area}

Deqing County is located in the west of Hangzhou-Jiaxing-Huzhou Plain in the Yangtze River Delta, 
and belongs to Huzhou City, Zhejiang Province, China. The western region of Deqing County is a branch of Tianmu Mountain, the terrain slopes from west to east, and the eastern region is plain. The land area of Deqing County is $938 \mathrm{~km}^{2}$, the east-west span is $56 \mathrm{~km}$, and the north-south span is $30 \mathrm{~km}$. There are 12 towns, of which Wukang Town is its political, economic and cultural center. By the end of 2016, there were 3 general hospitals, 12 health centers (seven branches), 133 health service stations in Deqing County (sown as Fig.1), and the resident population exceeded 320,000. Deqing County has the densely distributed transportation network that provide people with shorter commute distances.

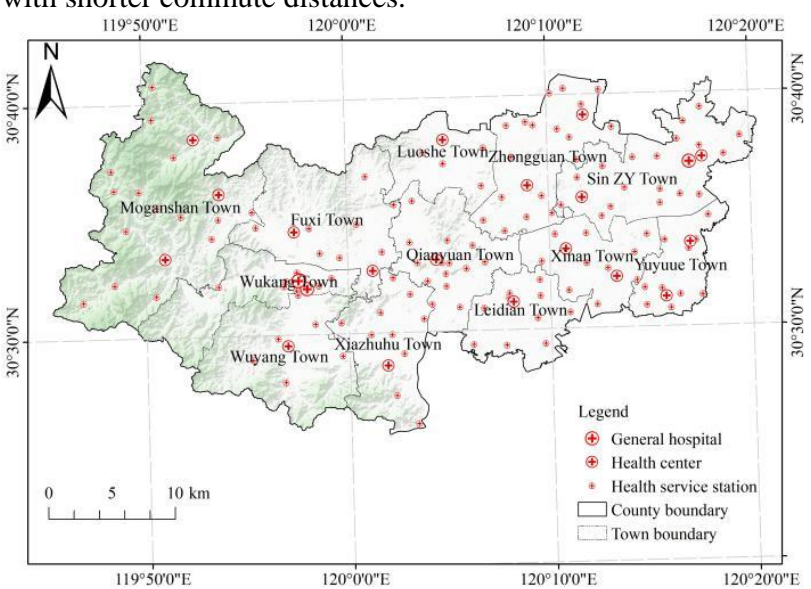

Figure 1. Spatial distribution of hospitals or health institution in Deqing County.

\subsection{Data Source}

In order to make the research results more accurate, this study almost exclusively makes use of data sources provided by government departments. For indicators using statistical data, we obtained county-level data for 2010-2017, including demographic data, death toll, number of infectious diseases, and so on.

The geographical location data of the county, township and village hospitals and road transportation network are provided by the Deqing County Geographic Information Center. Different levels of hospitals have different service functions. County-level general hospitals mainly provide surgical treatment services for people who have major diseases/injuries and need emergency assistance; township health centers provide people with treatment services of common diseases and frequentlyoccurring diseases as well as small-scale surgical; village health service stations provide treatment services for people with minor illness/injury who do not need emergency care. There are freeways, national highways, provincial highways, county \& township highways in the transportation network. Road density is twice the average density of Chinese roads.

The resolution of the population decomposition data is $30 \mathrm{~m}$, obtained by a geospatial disaggregation method based on fine building information. Due to topography, economic and political reasons, the population is mainly concentrated in Wukang Town of central city; the western mountainous areas is mainly used to develop tourism economy, so the population distribution is sparse and scattered; the population of the eastern plains is concentrated in Xinshi Town of the sub-central city and the industrial town of Qianyuan, and the rest of the area is evenly distributed.

\section{METHOD}

\subsection{Localization of Indicators}

The SDGs global indicator framework is based on global and national scales, mainly for monitoring and evaluation at the national level. But the research area is Deqing, which is a county-level area. The indicators of SDG 3 can not be fully adopted, so it is necessary to localize the indicators. In the process of localization, three aspects are mainly considered, i.e. whether the evaluation indicators are suitable for the study area; whether the research area has authoritative and reliable data for the selected indicators; whether the selected indicators can comprehensively express the health of the research area.

Based on SDGs global indicator framework (IAEG-SDGs, 2017), China's National Plan on Implementation of the 2030 Agenda for Sustainable Development (hereinafter referred to as the National Plan) (The State Council of the People's Republic of China, 2016), considering the geographical characteristics of Deqing, the feasibility of spatial scale conversion and the availability of data, this study localizes the SDG 3 indicators by three methods.

- Direct adoption. The directly adopted indicators have key components in the global indicator framework (there are 27 indicators in SDG 3,18 of which have comprehensive yet straightforward reference), such as concepts, definitions, calculation methods, etc., that are essential for measuring indicators, and can obtain reliable data from Deqing County.

- Modification. The modify indicators that do not have a reference standard in the global indicator framework or that differ from the national standard by reference standards.

- Abandoning. The discard indicators that do not conform to the actual conditions of Deqing County or have no relevant authoritative data

\subsection{Quantitative Calculation of Indicators}

3.2.1 Indicators of Statistical Data: The accuracy of the indicator results affects the subsequent assessment of the health of the study area. In order to ensure the accuracy of the method, for the directly selected indicators, reference is made to the "E-Handbook on Sustainable Development Goals Indicators Goal 3" prepared by the United Nations Statistics Division (UNSD) and the World Health Organization (WHO). This handbook addresses the growing need for information targeted towards national statisticians to collect, calculate, and monitor the SDGs using data produced by the national statistical systems. For example, indicator 3.4.1 (mortality rate attributed to cardiovascular disease, cancer, diabetes or chronic respiratory disease) is defined as the per cent of 30-year-old people who would die before their 70th birthday from cardiovascular diseases, cancer, diabetes, or chronic respiratory diseases. This indicator is calculated based on the life tables influenced by only the four non-communicable diseases (NCDs) (WHO, 2014) and applying the cause-specific death rate to each 5-year age range.

$$
{ }_{5} M_{x}=\frac{T D x+5}{T P x+5}
$$

where $\quad{ }_{5} M_{x}=$ mortality rate for each 5-year age group $x=30,35, \ldots 65$ $T D x+5=$ the total number of people who died from four NCDs between exact age $x$ and exact $(x+5)$ $T P x+5=$ the total population between exact age $x$ and exact $(x+5)$ 
Then calculate the mortality rate for each 5 -year group between the ages 30 and 70 , and translate the mortality rate into probability of dying between exact age and exact age.

$$
{ }_{5} q_{x}=\frac{{ }_{5} M_{x} \times 5}{1+{ }_{5} M_{x} \times 2.5}
$$

where ${ }_{5} q_{x}=$ the probability of death for each 5 year age group.

Finally, the probability of death is calculated between the ages of 30 to 70 , independent of other causes of death.

$$
N D M R=1-\prod_{x=30}^{65}\left(1-{ }_{5} q_{x}\right)
$$

where $\quad N D M R=$ the probability of death between 30 and 70 years.

The revised indicator (except indicator 3.8.1) is calculated with reference to the national statistical standards. For example, indicator 3.7.1 (contraceptive rate of married women of reproductive age) refers to the "13th Five-Year plan for the development of women and children in Zhejiang Province". The formula is as follows:

$$
M W R=\frac{M W_{n}}{P_{m}} \times 100 \%
$$

where $\quad M W R=$ the contraceptive rate of married women of reproductive age.

$M W_{n}=$ the number of married women of childbearing age who have adopted various contraceptive measures.

$P_{m}=$ the total number of married women of reproductive age.

3.2.2 Indicators of Geographic Information Data: Indicator 3.8.1 is the coverage of essential health services. It mainly measures the service capacity and fairness of health care facilities in Deqing County. Statistical data can only represent the average status of statistical objects in spatial regions, and it is difficult to reflect the true distribution in space (Monteiro, 2018; Wu, 2018). For indicators involving the spatial distribution and change of geographic information, spatial methods are often used (Liverman, 2018). Accessibility analysis was used to reveal the proportion of the population that can reach the nearest healthcare facilities and enjoy basic medical services from their homes at different time thresholds. Accessibility represents the convenience of reaching one point from another, and the accessibility of medical services is a study of the difference in the spatial distribution of medical resources (supply) and resident population (demand) (Mcgrail, Humphreys, 2009; Wang, 2011). This paper uses the roads at multi-levels (i.e., highways, national highways, provincial highways, county and township highways) to calculate accessibility. The design speed of highways at all levels refers to the "Technical Standards for Highway Engineering of the People's Republic of China (JTGB01-2014)". Due to unpredictable factors such as weather, traffic flow, etc., it was multiplied by the deceleration factor of 0.75 as the actual speed of the accessibility analysis ( $\mathrm{Li}, 2015)$. Adding the 30-meter grid population data obtained by the "areal interpolation weights method", the population coverage ratio of hospital accessibility is calculated.

\section{RESULTS AND ANALYSES}

\subsection{Result of Localization}

In the United Nations 2030 Agenda for Sustainable Development, SDG 3 has 13 targets and 27 indicators. After localization, 12 of them are not adopted, 15 indicators are selected, including 8 indicators are adopted directly (recorded as A) and 7 indicators are revised (recorded as R). According to the connotation of the selected indicators in SDG 3, it can be divided into three categories: Health Level, Disease Control \& Prevention, and Health Services. The details are shown in Table 1.

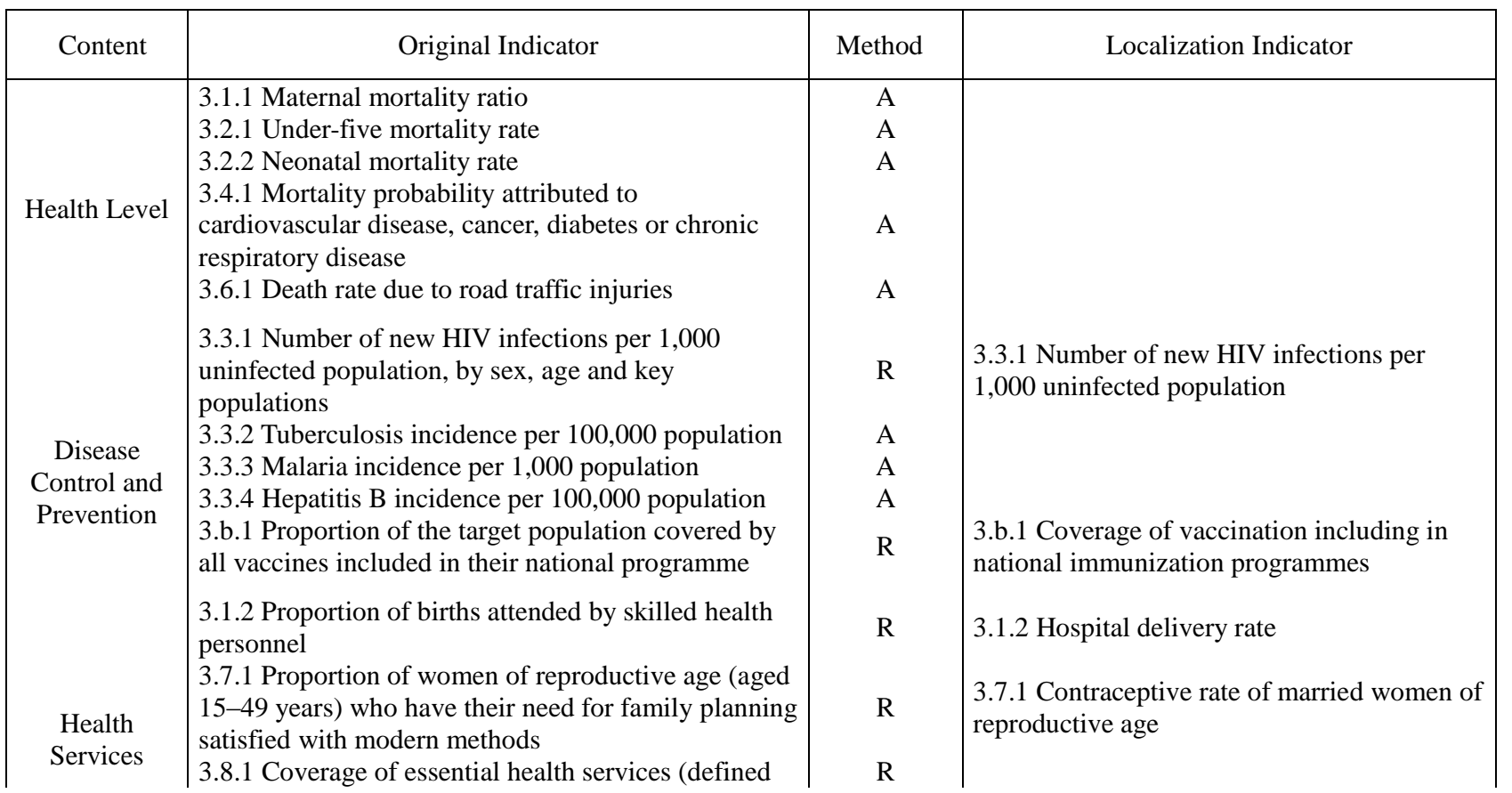




\begin{tabular}{|l|l|l|}
$\mid \begin{array}{l}\text { as the average coverage of essential services based on } \\
\text { tracer interventions that include reproductive, } \\
\text { maternal, newborn and child health, infectious } \\
\text { diseases, non-communicable diseases and service } \\
\text { capacity and access, among the general and the most } \\
\text { disadvantaged population) } \\
\text { 3.b.2 Total net official development assistance to } \\
\text { medical research and basic health sectors } \\
\text { 3.c.1 Health worker density and distribution }\end{array}$ & $\mathrm{R} \quad \begin{array}{l}\text { 3.b.2 Government health expenditure as a } \\
\text { proportion of GDP and government } \\
\text { expenditure } \\
\text { 3.c.1 The number of health workers per 1,000 } \\
\text { population }\end{array}$ \\
\hline
\end{tabular}

Table 1. SDG 3 localization results

\subsection{Result of Quantitative Calculation}

4.2.1 Indicators of Statistical Data: In 2010-2017, most of the disease incidence and mortality in Deqing County showed a decreasing trend. Only HIV infection rate showed an upward trend, but remained at a low level.

The Health Level according to the meaning of the indicator includes 5 statistical indicators. Focusing on the health of key population, providing some basic drugs free of charge for chronic diseases, building green channels for pregnant and parturient women, popularizing the fundamental knowledge of children's health, Deqing has been reducing mortality year by year. Therefore, in 2017 , the maternal mortality rate was 0 ; the mortality probability attributed to cardiovascular disease, cancer, diabetes or chronic respiratory disease dropped to $8.9 \%$ before the age of 70 ; the mortality rate of children under-five and neonatal decreased to $2.89 \%$ and $0.89 \%$; death rate due to road traffic injuries felled to $6.98 / 100,000$. Disease Control \& Prevention includes 5 statistical indicators. In 2017, the immunization program vaccination rate was above $97 \%$; the malaria incidence rate was 0 ; the incidence of tuberculosis and hepatitis B reduced to $26.53 / 100,000$ and $13.29 / 100,000$; the HIV infection rate was $0.0417 \%$. The Health Services consists of 4 statistical indicators. By integrating all medical resources in the county, Deqing has unified the deployment of medical resources which can be shared and interoperable. In 2017, the hospital delivery rate was $100 \%$; the contraceptive rate of married women of reproductive age increased to $92 \%$; the number of health technical personnel, licensed physicians \& physician assistants, registered nurses per 1,000 population was 7.56\%, 2.79\%o, 2.70\%; government health expenditure as a proportion of GDP and government expenditure reached $0.83 \%$ and $7.59 \%$, respectively.

4.2.2 Indicators of Geographic Information Data: The results of our accessibility analysis are shown in Fig.2. The accessibility of healthcare facilities is distributed in a ring-shaped manner centered on the target and spreading outward along the road. The time interval is 5 minutes. The convenience of accessibility is measured by the time taken by residents to reach healthcare facilities. Good accessibility means that it takes less time to reach the healthcare facility. Areas with good accessibility in general hospitals are concentrated in the central and eastern regions, and areas with poor accessibility are concentrated in the western mountains (Figure 2a). Due to the uniform distribution of health centers, accessibility in most areas is good, and only a small part of the western part of the mountain has poor accessibility (Figure $2 b$ ). There are a large number of health service stations, which are reasonably distributed in villages or communities, and most areas have good accessibility (Figure 2c).

Combined with the 30 -meter grid population data, it is found that healthcare facilities are concentrated in densely populated areas, and the distribution of medical institutions in dispersed areas is relatively scattered. The results calculated using the population data are shown in Table 2. Within 20 minutes, $56.27 \%$ of the residents could reach the nearest general hospital; $99.90 \%$ of the residents could reach the nearest health center; $100 \%$ of the residents could reach the nearest health service station (Figure 3).

In the "13th Five-Year Plan for the Establishment of Medical Institutions in Zhejiang Province" issued by the Zhejiang Provincial Health and Family Planning Commission, it is stipulated that each township should have a standardized township health center. In principle, according to the "20-minute service circle" (reaching the nearest health service station within 20 minutes), it is required to plan to set up a village clinic (community health service station). Deqing County has met the planning requirements.

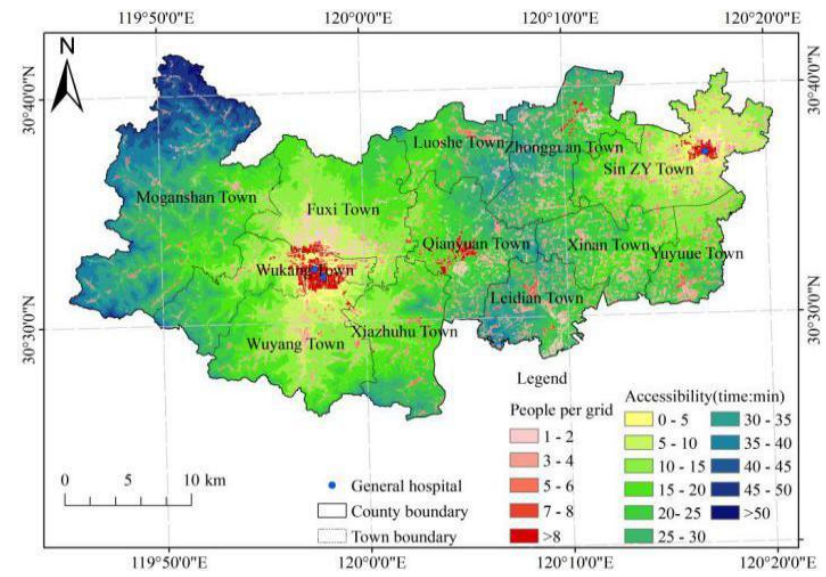

(a)

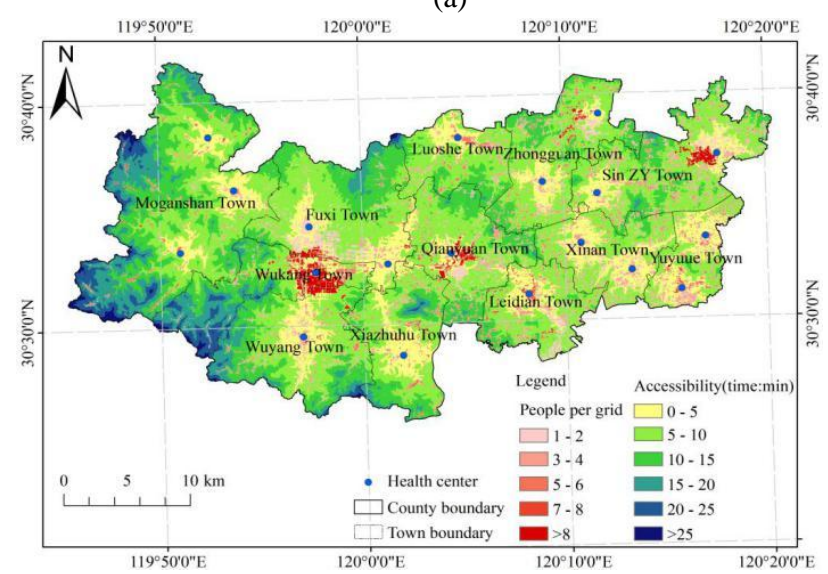

(b) 


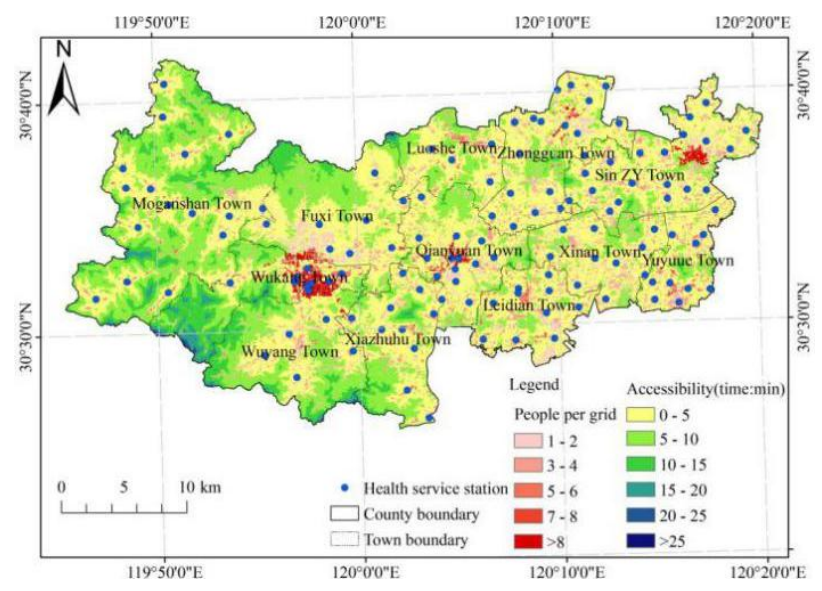

(c)

Figure 2. Accessibility of medical and health facilities based on 30m grid population density in Deqing County. (a) Accessibility of general hospitals; (b) Accessibility of health centers; (c) Accessibility of health service stations.

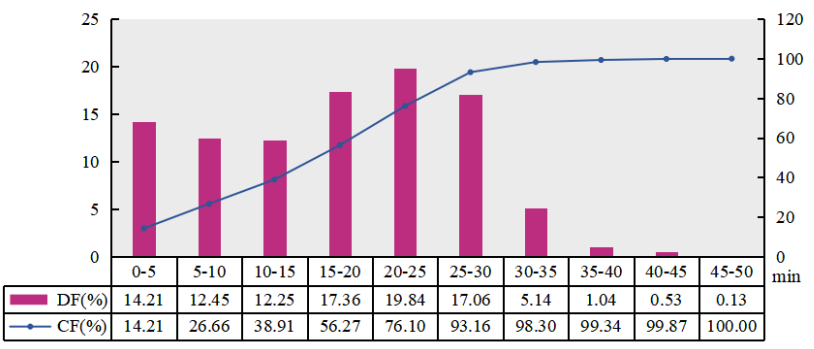

(a)

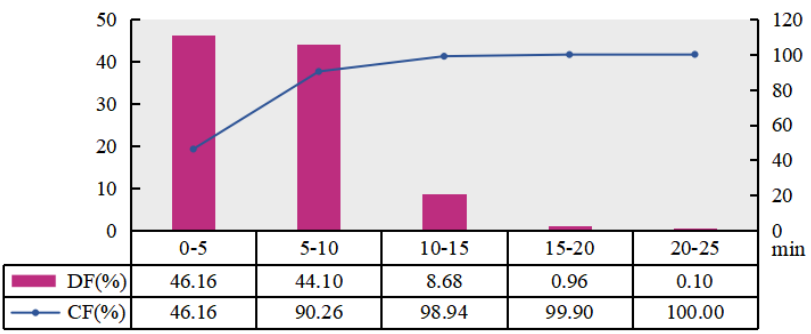

(b)

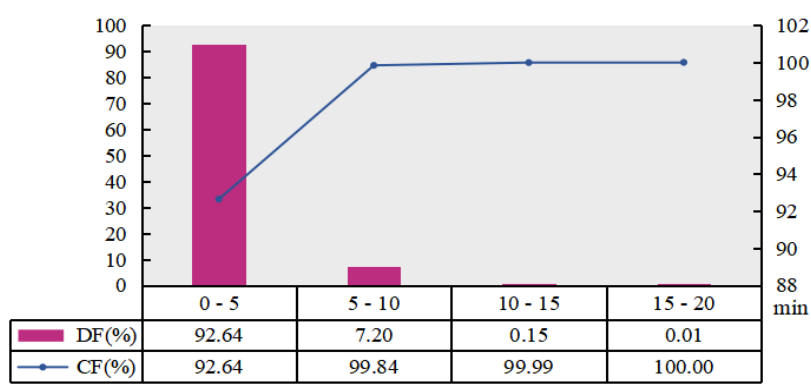

(c) population who could reach medical and health facilities within each time interval; (a) Distribution frequency and cumulative frequency of general hospitals; (b) Distribution frequency and cumulative frequency of health centers; (c) Distribution frequency and cumulative frequency of health service stations.

\subsection{Assessment}

To measure the level of quantitative results of health indicators and to reflect the health of Deqing County, we use the "SDGs Index and Dashboard" (Sustainable Development Solutions Network, Bertelsmann Stiftung, 2017) report issued by Bertelsmann Foundation and the United Nations' Sustainable Development Solutions Network (SDSN) in 2017 for evaluation. It is derived from the results of $157 \mathrm{UN}$ member states/regions by adjusting the indicators to the score range between 0 (lowest) and 100 (highest). The sores are divided into four segments, i.e., the top quarter (green, basically fulfilling the requirements of the indicator), the second quarter (yellow, to be upgraded), the third quarter (orange, challenging), and the bottom quarter (red, far from achieving the 2030 indicator requirements). Since the SDGs Index and Indicator Board does not fully cover the indicators that need to be evaluated in SDG 3, we could also use the quantitative requirements to be achieved until 2020 and 2030 respectively in the National Plan, multi-assessment (i.e., China level or world level), or others (i.e., the relevant criteria in national specification) to give appropriate evaluation results. If there is no comparability, no comparison will be made.

Of the 15 indicators, 10 indicators refer to the SDGs Index and Dashboard. For example, the indicator 3.2.1 (under-five mortality rate) had a quantified result of $2.89 \%$ in 2017 , and the grade in the indicator board was green $(\leq 25 \%)$; One indicator, 3.3.3 (malaria incidence per 1,000 population), refers to the goal of eliminating malaria by 2020 as set out in the National Plan; One indicator 3.3.4 (hepatitis B incidence per 100,000 population) is evaluated by multi-assessment, with reference to the China level in the 2017 China Health and Family Planning Statistical Yearbook; Indicator 3.8.1 refers to the construction standard of medical structure in the "13th Five-Year Plan for the Establishment of Medical Institutions in Zhejiang Province". Two indicators are not comparable and can not be assessed. For example, indicator 3.c.1 (the number of health workers per 1,000 population) is not comparable to the China level. Because with the improvement of the administrative level, the level and number of hospitals have also increased, the number of health workers has become more concentrated. The results are shown in Table 2. 12 of the 15 indicators of SDG 3 have achieved the quantitative requirements to be achieved until 2030, and only indicator 3.3.2 (tuberculosis incidence per 100,000 population) needs to be improved.

Overall, the entire achievement level of SDG 3 in Deqing County is good. In order to further improve the sustainable development level of Deqing, it is recommended that disease control and prevention center and other related departments in Deqing County establish related policies and take effective measures to lessen the incidence of tuberculosis in the future work of sustainable development.

Figure 3. Distribution frequency and cumulative frequency of

\begin{tabular}{|c|c|c|c|c|c|}
\hline Content & Indicators & Quantitative result & \multicolumn{3}{|c|}{ Evaluation reference } \\
\hline $\begin{array}{l}\text { Health } \\
\text { Level }\end{array}$ & $\begin{array}{l}\text { 3.1.1 Maternal mortality ratio } \\
\text { 3.2.1 Under-five mortality rate } \\
\text { 3.2.2 Neonatal mortality rate }\end{array}$ & $\begin{array}{l}0 * * \\
2.89 \% * * \\
0.89 \% * *\end{array}$ & $\begin{array}{l}\text { Green: } \leq 70 \\
\text { Orange: } 105<x \leq 140 \\
\text { Green: } \leq 25 \\
\text { Orange: } 37.5<x \leq 50 \\
\text { Green: } \leq 12\end{array}$ & $\begin{array}{l}\text { Yellow: } 70<x \leq 105 \\
\text { Red: }>140 \\
\text { Yellow: } 25<x \leq 37.5 \\
\text { Red: }>50 \\
\text { Yellow: } 12<x \leq 15\end{array}$ & \\
\hline
\end{tabular}




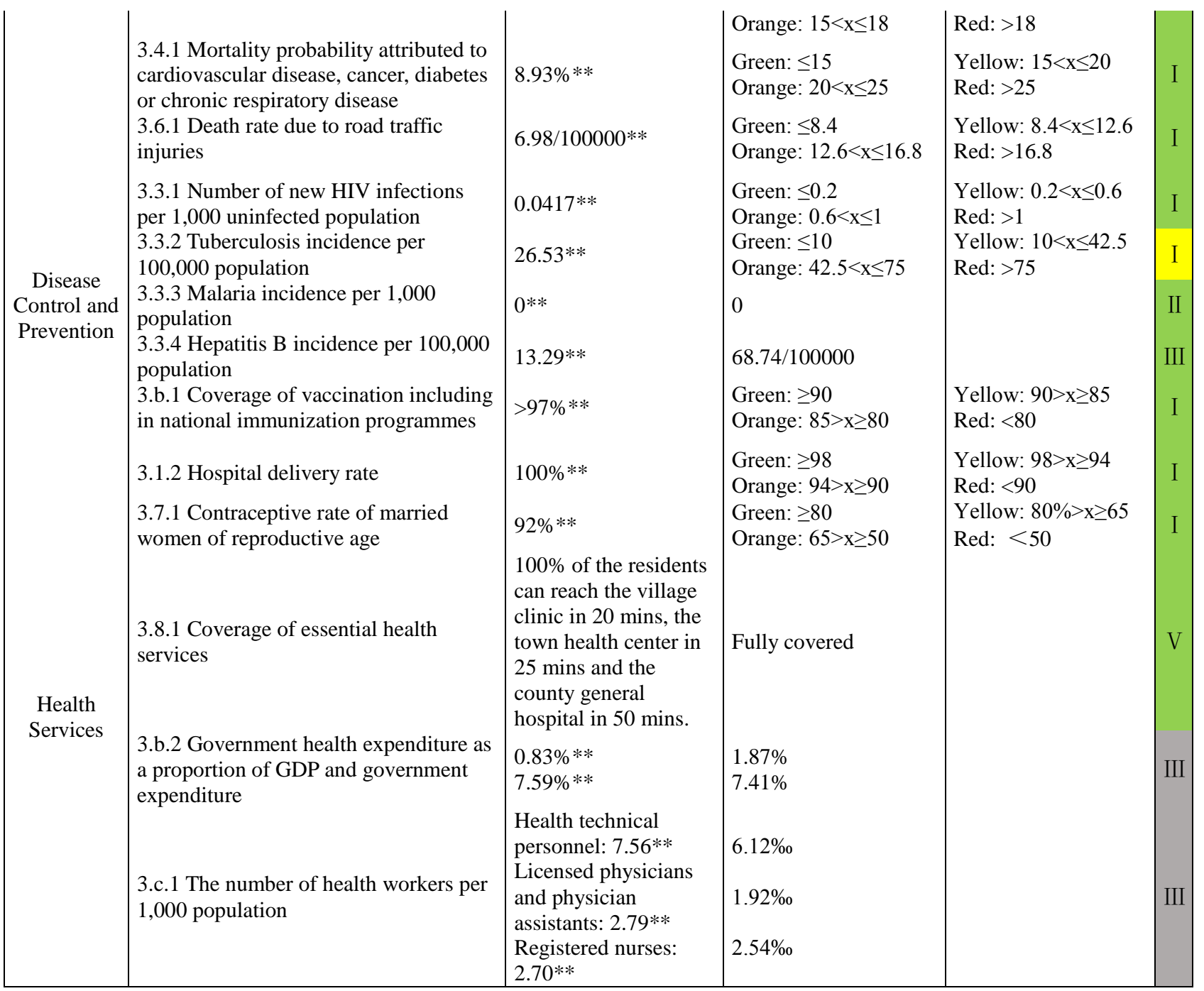

Table 2. Quantified indicators for SDG 3

Notes: I - "SDGs Index and Dashboard"; II - "National Plan"; III - the "2017 China Health and Family Planning Statistical Yearbook"; V - "13th Five-Year Plan for the Establishment of Medical Institutions in Zhejiang Province"

\section{CONCLUSION}

The sustainable development of healthy living is one of the basic guarantees for people's happy life. The assessment of this goal helps to monitor the level of healthy sustainable development in a country or region and is an important practice for advancing 2030 Agenda for Sustainable Development of the United Nations.

This study presents a complete method to measure the progress of SDG 3 in sub-nation level. First, considering the actual situation of Deqing County, the indicators of SDG 3 are localized according to the principles of adaptability, availability and accuracy, which makes the indicators better to measure the situation of Deqing County and the final assessment results more accurate. Second, the method of combining statistical and geospatial information is used to calculate the indicators. In particular, accessibility analysis and disaggregation population data are used to measure the indicator 3.8.1.can be more accurate than using demographic data. Finally, assess the gap between the indicators and the 2030 target, and measure the level of sustainable development of Deqing.

This study not only provides scientific basis for summarizing executing goal experience, working out existing problems and compiling improvement schemes, but also offers reference method and example for SDG 3 assessment and monitoring in other regions. Due to the lack of relevant experience and research on SDGs assessment of a small region, how to measure the completeness of SDG3 indicator selection and the effectiveness of localization are the focus of future research.

Funding: This work was supported by the National Natural Science Foundation of China (No. 41601456)

\section{REFERENCES}

Blackstone, S. R., Nwaozuru, U., Iwelunmor, J. I., 2017. An examination of the Maternal Factors Influencing Under-5 Mortality in Nigeria: Evidence from the 2013 Nigerian Demographic Health Survey. Global Public Health, 12(6): 744-756. doi: 10.1080/17441692.2016.1211166

Chen, J., Ren, H., Geng, W., Peng, S., Ye, F., 2018. Quantitative Measurement and Monitoring Sustainable Development Goals (SDGs) with Geospatial Information. Geomatics World, 25(01): 1-7. doi: 10.3969/j.issn.1672-1586.2018.01.001

Eduardo, G. P., Mariana, B. L., Naomi B, Dean, J., Felicia, K., 
Rafael, L., Gavin, Y., Jaime, S., 2016. Mexico's Path towards the Sustainable Development Goal for Health: an Assessment of the Feasibility of Reducing Premature Mortality by $40 \%$ by 2030. Lancet Global Health, 4 (10):714-725. doi: 10.1016/S2214-109X(16)30181-4

GBD 2015 SDG Collaborators, 2016. Measuring the Health-Related Sustainable Development Goals in 188 Countries: a Baseline Analysis from the Global Burden of Disease Study 2015. Lancet, 388(10053):1813-1850. doi: 10.1016/S0140-6736(16)31467-2

IAEG-SDG, 2017. Global indicator framework for the Sustainable Development Goals and targets of the 2030 Agenda for Sustainable Development. Available online: https://unstats.un.org/sdgs/indicators/Global\%20Indicator\%20Fr amework\%20after\%202019\%20refinement_Eng.pdf

Kuuire, V. Z., Kangmennaang, J., Atuoye, K. N., 2017. Timing and Utilisation of Antenatal Care Service in Nigeria and Malawi. Global Public Health, 12(6):711-727. doi: 10.1080/17441692.2017.1316413

Liverman, D. M., 2018. Geographic perspectives on development goals: Constructive engagements and critical perspectives on the MDGs and the SDGs. Dialogues in Human Geography, 8(2):168-185. doi: 10.3390/ijgi8010014

Li, Y., Zhang, Y., Li, J., 2015. Differential Analysis of Accessibility for Different Transportation Network in Guangzhou. Acta Sci. Nat. Univ. Sunyatseni, 54(02):133-140. doi: 10.13471/j.cnki.acta.snus.2015.02.025

Mcgrail, M., Humphreys, J., 2009. Measuring Spatial Accessibility to Primary Care in Rural Areas: Improving the Effectiveness of the Two-step Floating Catchment Area Method.

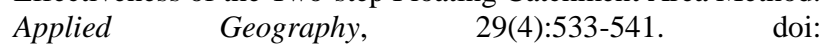
10.1016/j.apgeog.2008.12.003

Monteiro, J., Martins, B., Pires, J. M., 2018. A Hybrid Approach for the Spatial Disaggregation of Socio-economic Indicators. Int. J. Data Sci. Anal, 5, 189-211. doi: 10.1007/s41060-017-0080-z

Rood, E., Khan, A. H., Modak, P. K., Mergenthaler, C., Gurp, M., Blok, L., Bakker, M., 2019. A Spatial Analysis Framework to Monitor and Accelerate Progress towards SDG 3 to End TB in Bangladesh. ISPRS Int. J. Geo-Inf., 8(1). doi: 10.3390/ijgi8010014

Sustainable Development Solutions Network (SDSN), Bertelsmann Stiftung, 2017. SDG Index and Dashboards Report 2017 - Global Responsibilities: International Spillovers in Achieving the Goals. Available at: http://sdgindex.org/reports/2017/.

The State Council of the People's Republic of China, 2016. China's National Plan on Implementation of the 2030 Agenda for Sustainable Development. Available online: http://www.gov.cn/xinwen/2016-10/13/5118514/files/44cb9455 89874551a85d49841b568f18.pdf.

United Nations, 2015. Transforming Our World: The 2030 Agenda for Sustainable Development. Available online: https://unstats.un.org/sdgs/indicators/Global\%20Indicator\%20Fr amework\%20after\%202019\%20refinement_Eng.pdf

Wang, L. 2011. Analysing Spatial Accessibility to Health Care:
A Case Study of Access by Different Immigrant Groups to Primary Care Physicians in Toronto. Annals of GIS, 17(4). doi: 10.1080/19475683.2011.625975

WHO, 2014. NCD Global Monitoring Framework: Indicator Definitions and Specifications. Geneva. Available at: http://www.who.int/nmh/ncdtools/indicators/GMF Indicator D efinitions_FinalNOV2014.pdf?ua $=1$

World Health Organization, 2016. World Health Statistics 2016: Monitoring Health for the SDGs, Sustainable Development Goals. Available at: https://www.who.int/gho/publications/ world_health_statistics/2016/EN_WHS2016_TOC.pdf?ua=1

Wu, J., Wang, X., Wang, C., He, X., Ye, M., 2018. The Status and Development Trend of Disaggregation of Socio-economic Data. J. Geo Inf. Sci., 20, 1252-1262. doi: 10.12082/dqxxkx.2018.180137

Yu, C., Wang, L., 2017. United Nations Health-Related SDG Indicators and its Current Situation in China. Journal of Public Health and Preventive Medicine, 28 (01): 1-7.

Yu, C., Feng, T., 2018. Outlook the Goal of China Health-related SDG 2030. Journal of Public Health and Preventive Medicine, 29(05): 1-6. 